\title{
Montelukast, a cysteinyl leukotriene receptor antagonist, inhibits the growth of chronic myeloid leukemia cells through apoptosis
}

\author{
ANA ZOVKO $^{1 *}$, ELHAM YEKTAEI-KARIN $^{1 *}$, DANIEL SALAMON $^{2}$, \\ ANDERS NILSSON ${ }^{1}$, JONAS WALLVIK ${ }^{3}$ and LEIF STENKE ${ }^{1,4}$ \\ ${ }^{1}$ Department of Oncology-Pathology, Karolinska Biomics Center, Karolinska Institute; \\ ${ }^{2}$ Department of Women's and Children's Health, Karolinska Institute, Solna, S-171 76 Stockholm; \\ ${ }^{3}$ Department of Public Health and Clinical Medicine, Umeå University, S-901 85 Umeå; \\ ${ }^{4}$ Department of Hematology, Karolinska University Hospital, Solna, S-171 76 Stockholm, Sweden
}

Received July 18, 2017; Accepted April 12, 2018

DOI: $10.3892 /$ or.2018.6465

\begin{abstract}
The clinical outcome for patients with chronic myeloid leukemia (CML) has improved significantly with the introduction of tyrosine kinase inhibitors (TKIs). However, their curative potential appears limited, probably as a consequence of TKI-resistant leukemic stem cells (LSCs) that persist as a result of aberrant pathways independent of the well-established oncoprotein Bcr-Abl. One such pathway involves signaling through leukotrienes (LTs), bioactive compounds that have been suggested to play a role in several other malignancies. Cysteinyl LT1 receptor (CysLT1R) has been reported to be overexpressed in a number of solid cancers, and blocking of this receptor with the antagonist montelukast (treatment approved for bronchial asthma) has resulted in the killing of cancer cells. We recently demonstrated that montelukast, alone or in combination with imatinib, can effectively reduce the growth of CML cells, while normal bone marrow cells were left unaffected. Herein, we further investigated the importance of CysLT1R for the survival of CML cells and the mechanisms by which montelukast induces cell death. Knockdown of the CysLT1R of K562 cells with siRNA reduced their growth by $25 \%$. Montelukast had no effect on these cells, while it killed more than $50 \%$ of CysLT1Rexpressing cells. Growth inhibition exerted by imatinib was unaffected by CysLT1R status. Montelukast-induced killing of K562/JURL-MK1 CML cells was paralleled by Bax
\end{abstract}

Correspondence to: Professor Leif Stenke, Department of Oncology-Pathology, Karolinska Biomics Center, Z5:01, Karolinska Institutet, Solna, S-171 76 Stockholm, Sweden

E-mail: leif.stenke@ki.se

*Contributed equally

Key words: chronic myeloid leukemia, tyrosine kinase inhibitors, leukotrienes, montelukast, apoptosis overexpression, cytochrome $c$ release, PARP-1 cleavage, and caspase- 3 activation, an event further increased in a setting where montelukast was added to imatinib. Wnt/ $\beta$-catenin signaling was activated by CysLT1R and we observed that montelukast could induce proteins in this pathway, a finding of relevance for LSC survival. Thus, montelukast, employed at in vivo-like concentrations, induces the killing of CML cells through apoptotic pathways and may provide an additional, novel therapeutic possibility in CML.

\section{Introduction}

Chronic myeloid leukemia (CML) is a malignancy characterized by a reciprocal translocation $(9: 22)$ resulting in the Philadelphia chromosome, which triggers the formation of the fusion oncoprotein Bcr-Abl. This is a constitutively active tyrosine kinase with leukemogenic properties, required for the pathogenesis of CML (1). The inhibition of Bcr-Abl by imatinib and other tyrosine kinase inhibitors (TKIs) has fundamentally improved the outcome for patients with CML in the chronic phase $(2,3)$. However, leukemic stem cells (LSCs) seem to be capable of surviving even after continuous, long-term TKI administration and the discontinuation of TKI in most cases leads to disease recurrence. Thus, there is a need to improve current CML therapy and to focus on therapeutic options that may lead to eradication of LSCs, and total cure. Other signaling pathways, in addition to that of Bcr-Abl, have been found to be aberrantly expressed in CML cells and may thus be crucial for the survival and maintenance of LSCs. Such pathways include Wnt/ $\beta$-catenin signaling, the tumor suppressor gene PML, Forkhead box subgroup $\mathrm{O}$ transcription factors, sonic hedgehog signaling, prosurvival protein $\mathrm{Bcl} 2$ and JAK/STAT signaling (4).

Formation of bioactive leukotrienes (LTs), which have a recognized role in inflammatory processes (5), is another pathway suggested to be involved in initiation and maintenance of LSCs (4). In mice, the arachidonate 5-lipoxygenase (5-LO) gene (Alox5), active in an early stage of LT synthesis, has been reported to be upregulated in CML LSCs rendering 
them resistant to TKI treatment. While the presence of Alox5 is crucial for LSCs, it did not significantly affect the functions of normal hematopoietic stem cells $(6,7)$. In the human, 5-LO converts arachidonic acid into the intermediate LTA4, for further metabolism into $\mathrm{LTB}_{4}$ and the cysteinyl (Cys) containing leukotrienes $\mathrm{LTC}_{4}, \mathrm{LTD}_{4}$ and $\mathrm{LTE}_{4}$. The biological actions of CysLTs are mediated through activation of CysLT1 and CysLT2 receptors (8). Overexpression of the cysteinyl LT1 receptor (CysLT1R) has been reported in renal cell carcinoma and cancer of the bladder, prostate, testes, brain, breast and colorectal region (9-13). High expression of CysLT1R in breast and colorectal cancer is associated with poor prognosis $(9,12)$. Cysteinyl leukotriene signaling is involved in many tumorigenesis cancer-related processes: proliferation, migration, invasion, angiogenesis, genome instability, deregulation of cellular energetics and apoptosis (11).

Montelukast is a selective oral CysLT1R antagonist, approved in clinical practice for several years as a safe and effective treatment for patients with asthma and allergic rhinitis (14). In addition, a role in apoptosis induction has recently been highlighted in several malignancies. Montelukast inhibits the growth of urological, colorectal and renal cell carcinoma by induction of apoptosis (10,15-17). Montelukast was found to induce reduced colony formation, apoptosis and G1 arrest in colon cancer cells and decreased the growth of mouse xenografts (18). In neuroblastoma cell lines, montelukast induced caspase-dependent apoptosis and cell cycle arrest in the subG1 phase (19). Montelukast also was found to inhibit the cell migration and invasion of human glioblastoma cells by suppressing MMP-2 and MMP-9 activities (20).

Our group has previously described that human CML cells have a high capacity to synthesize bioactive LTs and that LTs are capable of stimulating normal myeloid progenitor cell growth $(21,22)$. Recently, we also showed that physiological concentrations of the CysLT1R antagonist montelukast, alone or together with imatinib, induced a clear and dose-dependent inhibition of the growth of human CML cells, while normal bone marrow cells and fibroblasts were unaffected (23). Herein, we further analyzed the mechanisms underlying the cytotoxic activity exerted by montelukast on CML cells by assessing its relation to receptor expression and induction of key proteins linked to apoptotic events.

One of the pathways that CysLT1 signaling modifies is Wnt/ $\beta$-catenin signaling. This pathway has been shown to be important for development and survival of CML LSCs and potentially represents a therapeutic target in CML treatment $(24,25)$. Herein, we showed that montelukast can indeed alter Wnt/ $\beta$-catenin signaling, indicating that inhibition of $\beta$-catenin could be a key downstream mechanism for this compound in CML.

\section{Materials and methods}

Cell lines and inhibitors. CML cell lines (K562 and JURLMK1) were obtained from Leibniz-Institute DSMZ-German Collection of Microorganisms and Cell Cultures (Braunschweig, Germany) and maintained in RPMI-1640 medium with 10\% FBS, 2 mM L-glutamine (Invitrogen; Thermo Fisher Scientific, Inc., Carlsbad, CA, USA) Pen Strep (Gibco; Thermo Fisher Scientific, Inc.). The CysLT1R antagonist montelukast and imatinib were purchased from Selleck Chemicals (Houston, TX, USA).

Proliferation assay. Cell proliferation of JURL-MK1 cells was measured using the MTT cell proliferation assay according to the manufacturer's instructions as previously described (23). Cells were seeded in triplicate in flat-bottomed 96-well plates at 30,000 cells/well and treated for $72 \mathrm{~h}$ in the presence of $1 \mu \mathrm{M}$ montelukast and/or 0.1 imatinib $\mu \mathrm{M}$.

siRNA knockdown of CysLT1R expression. K562 cells were transfected with $100 \mathrm{nM}$ CysLT1R siRNA (Santa Cruz Biotechnology, Inc., Santa Cruz, CA, USA) for $96 \mathrm{~h}$ using Dharmafect. Stealth RNAi negative control duplexes (Invitrogen; Thermo Fisher Scientific, Inc.) were used as a negative control for transfection. Ablation of CysLT1R by siRNA was validated using western blotting as described below. Non-transfected cells, cells transfected with CysLT1R siRNA or Stealth RNAi negative control duplexes were transferred to a 96-well plate and treated with 2 and $3 \mu \mathrm{M}$ montelukast or $1 \mu \mathrm{M}$ imatinib for $24 \mathrm{~h}$ and cell viability was tested with trypan blue staining.

Analysis of apoptotic morphology and cytochrome c staining. K562 cells were treated with $2 \mu \mathrm{M}$ montelukast for 24 and $48 \mathrm{~h}$. Imatinib $(1 \mu \mathrm{M})$-treated cells were used as a positive control for induction of apoptotic morphology. Cells $(20,000)$ were resuspended in $100 \mu \mathrm{l}$ PBS and cytospinned onto glass sides at $26 \mathrm{x}$ g for $4 \mathrm{~min}$. Glass slides were fixed in ice-cold methanol for 3 min followed by ethanol gradient (100, 85 and $70 \%$ ) for 2 min each and kept at $-20^{\circ} \mathrm{C}$. Nuclear morphology of cells was examined by staining with 4,6'diamidino-2-phenylindole dihydrochloride (DAPI) (Vector Laboratories, Inc., Burlingame, CA, USA). Apoptosis was defined by the presence of fragmented nuclei. In total, 200 cells were counted and the percentage of apoptotic cells was presented.

In order to analyze the release of cytochrome $c$ from mitochondria, K562 cytospins were blocked with buffer (3\% BSA, $0.2 \%$ Triton $\mathrm{X}-100,10 \mathrm{mM}$ HEPES, $\mathrm{pH}$ 7.4) for $60 \mathrm{~min}$ and stained with the primary antibody against cytochrome $c$ (Cell Signaling Technology, Danvers, MA, USA) for $16 \mathrm{~h}$ at $4^{\circ} \mathrm{C}$. Cytospins were incubated with Alexa 488 secondary antibody (Invitrogen; Thermo Fisher Scientific) and counterstained with DAPI for nuclear visualization. Fluorescence microscope Axio Imager.Z2 (Zeiss AG, Oberkochen, Germany), equipped with a 100-W mercury lamp, a CCD camera (C4742-95, Hamamatsu) was used.

Analysis of caspase activation. Active caspase-3 level (a marker of cells undergoing apoptosis) was measured in K562 cells treated with 2 and $4 \mu \mathrm{M}$ montelukast for $24 \mathrm{~h}$ with PE Active Caspase-3 Apoptosis kit (BD Biosciences, San Jose, CA, USA) according to manufacturer's protocol by flow cytometry, using a CyAn ADP Analyzer (Beckman Coulter, Inc., Brea, CA, USA). The results were analyzed with FlowJo software, version 9.4.11 (Tree Star, Inc., Ashland, OR, USA). In order to ascertain whether cell death induced by montelukast is caspase-dependent, we treated cells with Z-VAD with or without montelukast. Cells were pretreated with $50 \mu \mathrm{M}$ Z-VAD for $30 \mathrm{~min}$ and then montelukast $(2 \mu \mathrm{M})$ was added and 
treated for additional $72 \mathrm{~h}$. Cell viability was measured using the MTT cell proliferation assay, as previously described (23).

Western blot analysis. To assess apoptosis induction, K562 and JURL-MK1 cells were treated with 2, 3 or $5 \mu \mathrm{M}$ montelukast for $8 \mathrm{~h}$. Alterations in Wnt $/ \beta$-catenin signaling were examined in K562 cells treated with $30 \mathrm{nM}$ montelukast for 15, 60, 90 and $180 \mathrm{~min}$. Whole-cell lysates were prepared in RIPA buffer (50 mM Tris-HCl, pH 7.4, $150 \mathrm{mM} \mathrm{NaCl}, 0.5 \%$ Igepal, $5 \mathrm{mM}$ EDTA and $0.1 \%$ SDS) and western blot analysis was performed as previously described (23). The following primary antibodies were used: CysLT1R (120500; Cayman Chemicals, Ann Arbor, MI, USA); PARP1 (H250; sc-7150; Santa Cruz Biotechnology); Bax (2772), $\beta$-catenin (9582), phospho- $\beta$-catenin (9561), $\beta \operatorname{TrCP}$ (4394; all from Cell Signaling Technology); c-myc (ab56; Abcam, Cambridge, UK). Antibody against $\beta$-tubulin (T7816; Sigma-Aldrich, Stockholm, Sweden) was used as control of equal loading. IR-Dye-linked secondary antibodies (926-32211 and 926-68070; LI-COR Biosciences, Lincoln, NE, USA) were used to image bands on the Odyssey platform.

Ubiquitination of $\beta$-catenin. Whole-cell lysates of K562 cells treated with $30 \mathrm{nM}$ montelukast were obtained at 15 , 60 and $90 \mathrm{~min}$ as described above. Lysates were subjected to immunoprecipitation using magnetic Dynabeads Protein A (10006D; Invitrogen; Thermo Fisher Scientific, Inc.) and anti$\beta$-catenin antibody (610154; BD Transduction Laboratories, San Jose, CA, USA), according to the manufacturer's instructions. Binding between $\beta$-catenin and $\beta-\operatorname{TrCP}$ was analyzed by immunoblot analysis as described above.

Statistical analysis. All statistical analyses were performed using Prism Software (GraphPad Software, Inc., La Jolla, CA, USA) and the statistical significance of data was determined as ${ }^{*} \mathrm{P}<0.05 ;{ }^{* *} \mathrm{P}<0.01 ;{ }^{* * *} \mathrm{P}<0.001$ (as indicated in the figures). For comparison between two groups, either a paired or unpaired $\mathrm{t}$-test (Student's t-test) was used. When three or more groups were compared, ANOVA followed by Tukey HSD post-hoc test was used. All values are expressed as the mean \pm standard error of the mean (SEM).

\section{Results}

CysLT1R expression and importance for montelukast cytotoxicity. We previously showed clear expression of CysLT1R in K562, KU812 and KCL22 CML cells (23). To show the importance of CysLT1R for the growth of CML cells, the receptor was knocked down using siRNA in K562 cells. After $96 \mathrm{~h}$, this knockdown reduced the receptor expression by approximately $80 \%$, while control cells showed maintainence of receptor expression (Fig. 1A). Depletion of CysLT1R resulted in a 25\% decrease in K562 cell growth, as compared to the control cells and to cells exposed to nontarget siRNA ( $\mathrm{P}=0.05)$ (Fig. 1B). Next, untransfected cells and cells transfected with CysLT1R siRNA or non-target siRNA were treated with montelukast or imatinib for $24 \mathrm{~h}$. The growth of cells with knocked-down CysLT1 receptor was unaffected by $2 \mu \mathrm{M}$ montelukast, while this receptor antagonist significantly reduced the viability of both cell lines exposed to non-target siRNA (by 50\%) and control cells
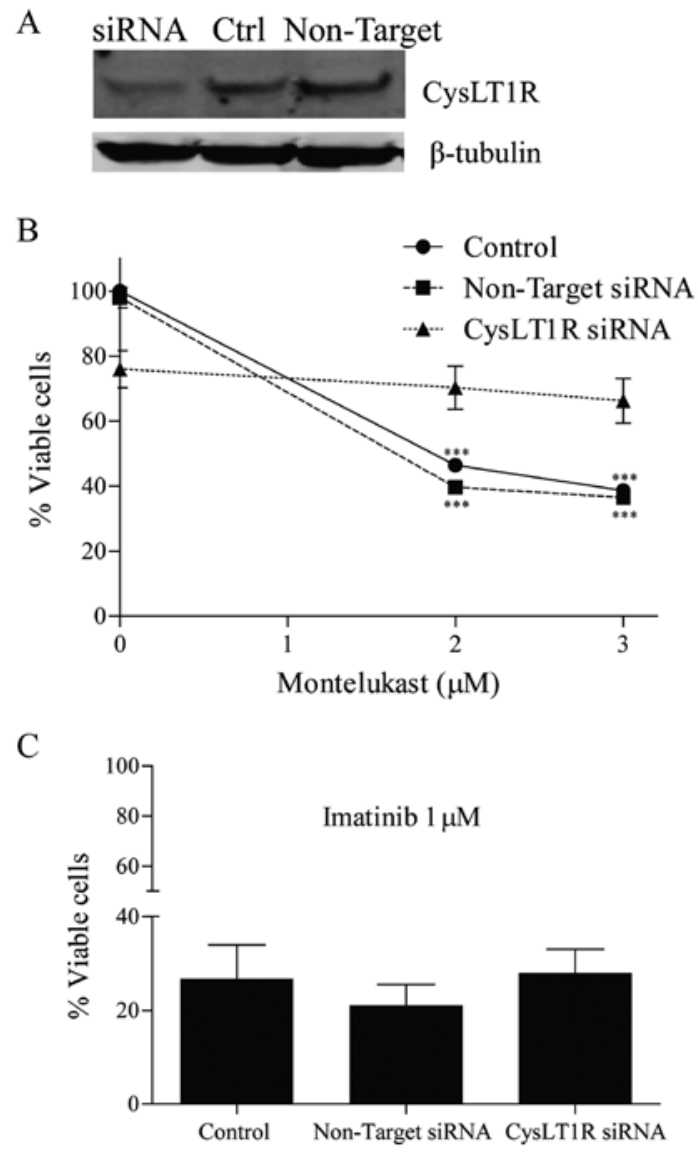

Figure 1. Importance of the CysLT1 receptor for montelukast toxicity. (A) K562 cells were transfected with $100 \mathrm{nM}$ CysLT1R siRNA or non-target siRNA for $96 \mathrm{~h}$ and knockdown of CysLT1R was validated using western blotting. Control cells, cells transfected with non-target siRNA (negative control) or CysLT1R siRNA were treated with montelukast $(2$ or $3 \mu \mathrm{M})$ (B) or $1 \mu \mathrm{M}$ imatinib (C) for $24 \mathrm{~h}$ and cell viability was examined by trypan blue staining. Data, mean \pm SEM of three technical replicates. ${ }^{* * *} \mathrm{P}<0.001$.

without siRNA (by 54\%) (Fig. 1B). Using $3 \mu \mathrm{M}$ montelukast, $62 \%$ of control cells and $63 \%$ of cells with non-target siRNA died, but only $14 \%$ of cells exposed to CysLT1R siRNA. Imatinib-induced inhibition of cell growth was similar in all three cell subpopulations (Fig. 1C).

Montelukast induces the apoptosis of K562 and JURL-MK-1 cells. To understand the mechanism by which montelukast induces growth prevention in CML, cell morphology was examined in the K562 cells. Montelukast induced apoptotic morphology in $22 \%$ of $\mathrm{K} 562$ cells after $24 \mathrm{~h}$ and in $32 \%$ after $48 \mathrm{~h}$ of treatment. Imatinib was used as a positive control and induced apoptotic morphology in 32\% and 35\% cells after 24 and $48 \mathrm{~h}$, respectively (Fig. 2).

Next, cytochrome $c$ release from mitochondria was examined. Treatment with montelukast, as well as with imatinib, caused cytosol localization of cytochrome $c$ (Fig. 3A). Release of cytochrome $c$ leads to activation of caspases and cleavage of the caspase-3 substrate PARP-1. Montelukast treatment resulted in PARP-1 protein cleavage in the K562 cells. Ratio of cleaved vs. full length PARP-1 increased in a dose dependent manner (Fig. 3B). Furthermore, we observed a dose-dependent increase in proapoptotic Bax protein signal in K562 cells upon montelukast treatment (Fig. 3B). The growth of JURL-MK1 

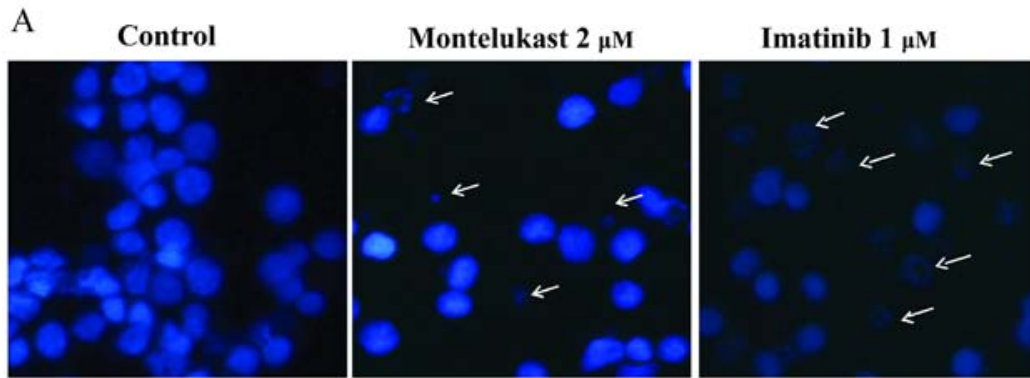

B

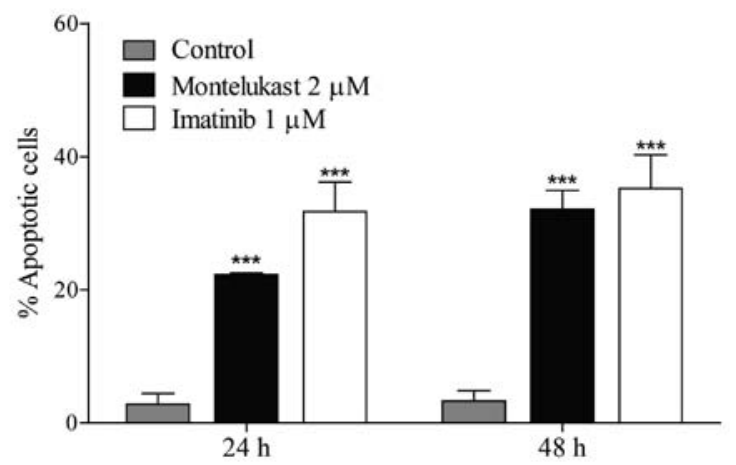

Figure 2. Analysis of apoptotic morphology. (A) K562 cells were treated with montelukast $2 \mu \mathrm{M}$ or imatinib $1 \mu \mathrm{M}$, and nuclear morphology of cells was examined with DAPI staining. (B) The percentage of cells displaying apoptotic morphology after 24 and $48 \mathrm{~h}$ of treatment was quantified in 200 cells. Data, mean \pm SEM of three technical replicates. ${ }^{* * *} \mathrm{P}<0.001$.
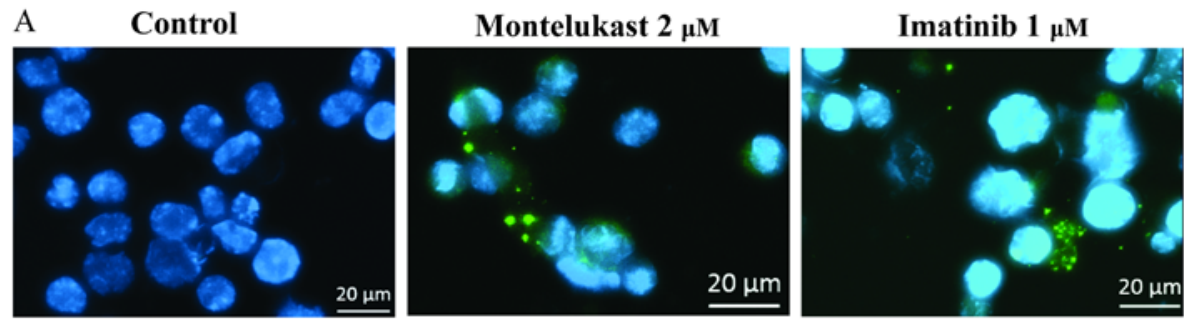

B
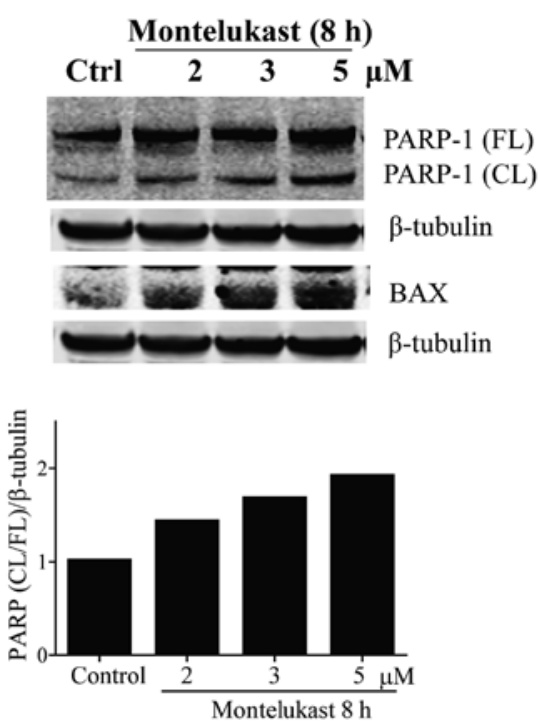

$\mathrm{C}$

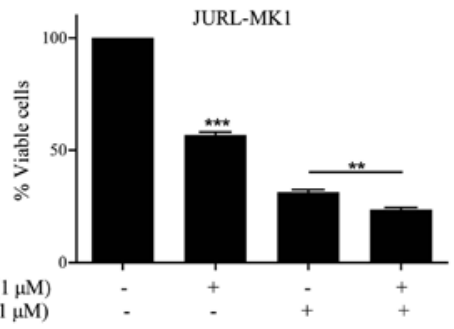

D
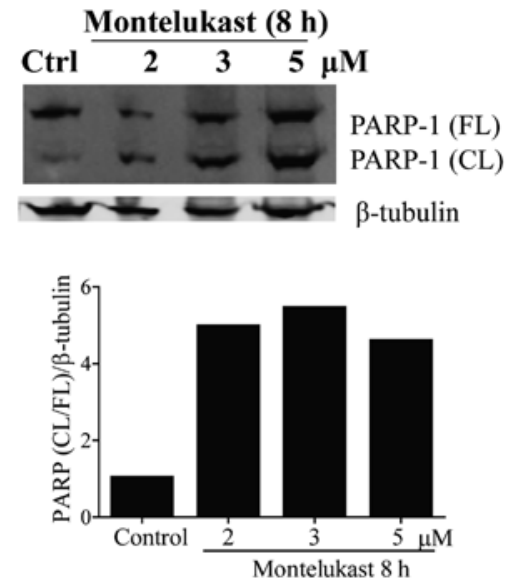

Figure 3. Montelukast induces apoptosis in K562 and JURL-MK1 cells. (A) Cytochrome $c$ release was examined by immunofluorescence staining of K562 cells after treatment with $2 \mu \mathrm{M}$ montelukast or $1 \mu \mathrm{M}$ imatinib for $24 \mathrm{~h}$. Blue, DAPI staining of nucleus; green, cytochrome $c$. (B) PARP-1 cleavage and expression of proapoptotic Bcl-2 family member Bax was examined in K562 cells treated with montelukast; cleavage of PARP-1 was quantified. (C) Growth inhibitory effects on JURL-MK1 cell line by imatinib and montelukast, administered as single drug or in combination. Data, mean of three independent experiments \pm SEM. Treatment with montelukast was compared with untreated control, while combination treatment with imatinib and montelukast was compared with imatinib alone. (D) PARP-1 cleavage was examined in JURL-MK1 cells treated with montelukast; cleavage of PARP-1 was quantified. The illustrated blots are representative of at least two separate experiments. ${ }^{* *} \mathrm{P}<0.01 ;{ }^{* * *} \mathrm{P}<0.001$. 
A

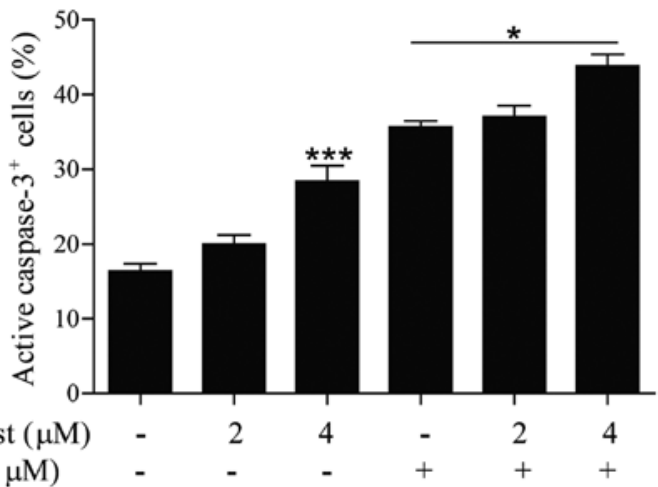

B

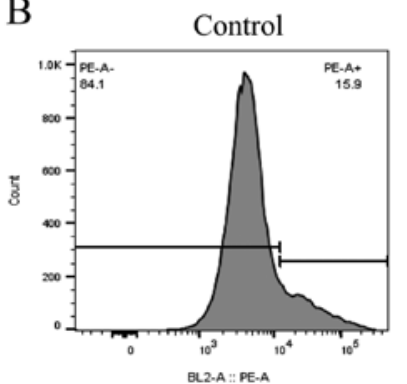

Imatinib $1 \mu \mathrm{M}$
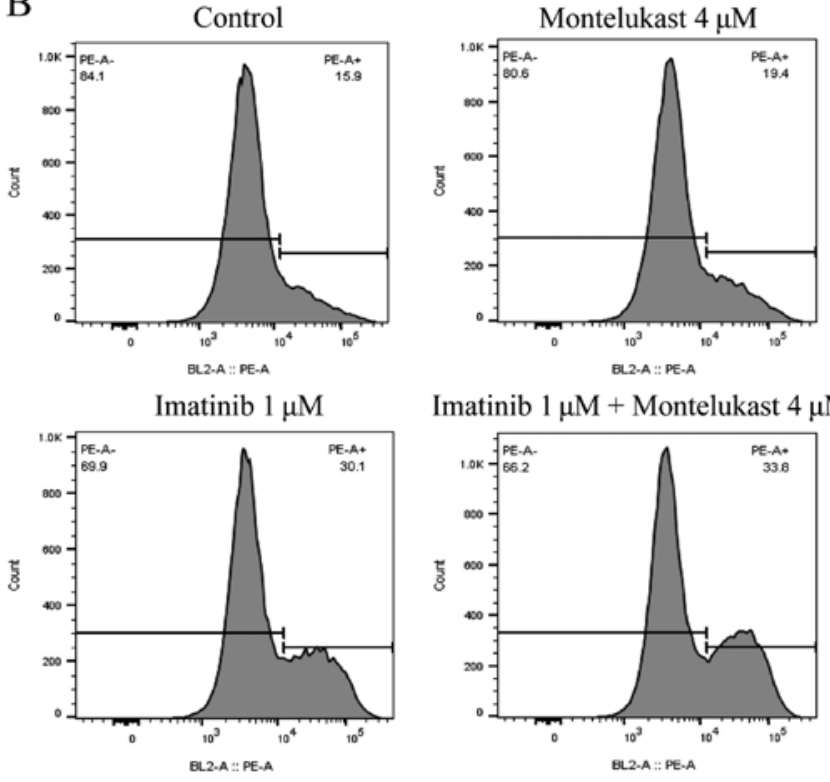

Imatinib $1 \mu \mathrm{M}+$ Montelukast $4 \mu \mathrm{M}$

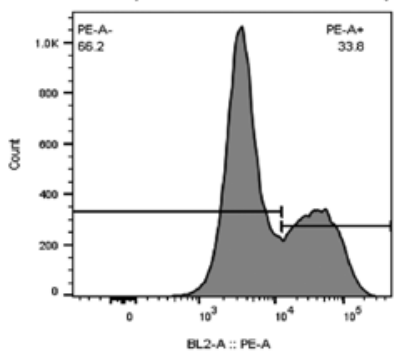

$\mathrm{C}$

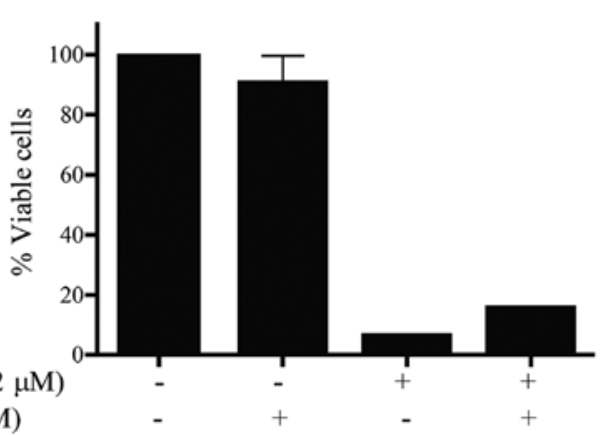

Montelukast $(2 \mu \mathrm{M})$

$\mathrm{Z}-\mathrm{VAD}(50 \mu \mathrm{M})$

Figure 4. Caspase- 3 activation in the K562 cell line. (A) K562 cells were treated with 2 or $4 \mu \mathrm{M}$ montelukast with or without imatinib for $24 \mathrm{~h}$, and caspase-3 activity was analyzed by flow cytometry. (B) Representative flow cytometry histogram showing cellular caspase 3 -activity in montelukast and/or imatinib-treated K562 cells. Data shown are one representative out of three replicates. (C) K562 cells were pretreated with $50 \mu \mathrm{M}$ Z-VAD for 30 min followed by $2 \mu \mathrm{M}$ montelukast for an additional $72 \mathrm{~h}$. Cell viability was measured using the MTT cell proliferation assay and is expressed as the percentage of cell survival compared to the control. Data, mean of three independent experiments \pm SEM. ${ }^{*} \mathrm{P}<0.05 ;{ }^{* * * *} \mathrm{P}<0.001$.

cells was significantly inhibited by montelukast, and when combined with imatinib the receptor antagonist induced further growth inhibition (Fig. 3C). PARP-1 protein was also cleaved in JURL-MK-1 cells treated with montelukast (Fig. 3D). Montelukast $(4 \mu \mathrm{M})$ also induced significant caspase-3 activa-

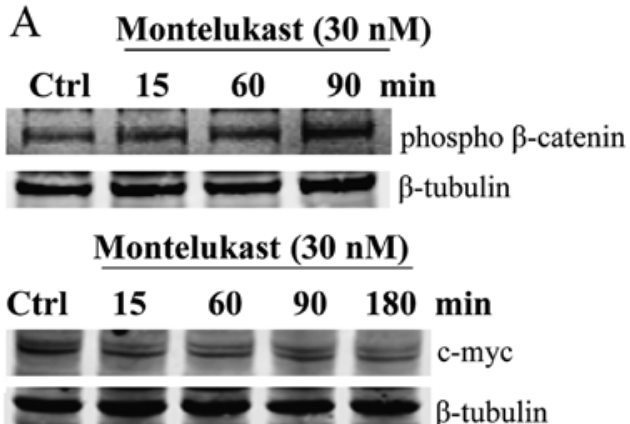

\section{B IP: $\beta$-catenin \\ Montelukast (30 nM)

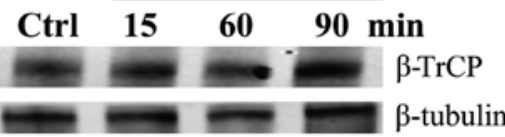

Figure 5. Montelukast induces alterations in the Wnt/ $\beta$-catenin signaling pathway. (A) K562 cells were incubated with $30 \mathrm{nM}$ montelukast, and cell extracts were analyzed by western blotting using phospho $\beta$-catenin and c-myc antibodies. (B) K562 cells were incubated with $30 \mathrm{nM}$ montelukast, and whole lysate was subjected to immunoprecipitation (IP) using $\beta$-catenin antibody. Anti $\beta$-TrCP antibody was used to detect binding between $\beta$-catenin and $\beta$-TrCP.

tion (Fig. 4A and B). Imatinib, which was used as a positive control for apoptosis induction, activated caspase-3 but when used in combination with $4 \mu \mathrm{M}$ montelukast, caspase-3 was further activated. Moreover, the caspase inhibitor Z-VAD was able to partially (although not statistically significant according to ANOVA test) inhibit montelukast-induced cell death (Fig. 4C).

Montelukast induces alterations of Wnt/ $\beta$-catenin signaling. In the absence of Wnt signaling, $\beta$-catenin is phosphorylated and polyubiquitinated by $\beta$-TrCP, leading to degradation by the proteasome. Montelukast treatment induced phosphorylation of $\beta$-catenin in a time-dependent manner, as well as decreased expression of downstream target c-myc (Fig. 5A). Immunoprecipitation with $\beta$-catenin revealed that montelukast enhanced the interaction between $\beta$-catenin and ubiquitin ligase $\beta$-TrCP (Fig. 5B).

\section{Discussion}

The cysteinyl LT1 receptor (CysLT1R) has been reported to be overexpressed in several carcinomas, a finding often linked to an inferior clinical prognosis $(9,12)$. The action of CysLT1R can be blocked through antagonist binding to the receptor $(10,18)$.

In the present study, we examined whether the expression of CysLT1R is crucial for the toxic effect exerted by the CysLT1R antagonist montelukast. Previously, we demonstrated that this antagonist has a clear inhibitory effect on the growth of the CML cell lines K562, KU812 and KCL22, with $\mathrm{IC}_{50}$ concentrations ranging between 1 and $2 \mu \mathrm{M}$. CysLT1R was expressed in all three cell lines (23). This indicates that an adequate presence of the receptor might be a prerequisite for the toxic, or cell inhibitory effect of the antagonist. In order to prove our hypothesis, we knocked down the CysLT1R receptor in K562 cells utilizing 
siRNA. When suppressing the receptor montelukast induced only minor effects on the survival of these CML cells, excluding off-target effects of the antagonist. In contrast, imatinib showed a consistent growth inhibitory effect on the CML cells, regardless of their CysLT1R receptor status. Moreover, we also showed that the presence of CysLT1R appears to be of importance for the overall survival of K562 cells, since cells with siRNA CysLT1R had a reduced viability by approximately $25 \%$. It is important to note that the knockout was not complete; approximately $20 \%$ of the receptor was still detectable after knockdown. This may provide an explanation why $75 \%$ of the K562 cells remained alive, in spite of (relative) CysLT1R absence.

Several studies performed in different malignancies have shown that montelukast is able to induce cell apoptosis $(10,15-19)$. In order to further understand the mechanisms behind montelukast-induced cytotoxicity in CML we examined the morphology of K562 cells. Montelukast caused prominent apoptotic morphology of the cell nuclei, similar to that induced by imatinib, which we used as a positive control. It is known that the proapoptotic Bax protein is overexpressed and the mitochondrial membrane permeabilized at an early stage of apoptosis, leading to release of cytochrome $c$ and activation of caspases (26). We noted that montelukast, in a dose-dependent manner, induced an overexpression of Bax. We further observed cytochrome $c$ release from cells treated with montelukast, as well as from cells treated with imatinib. Montelukast also caused PARP-1 cleavage and caspase-3 activation in a dose-dependent manner. Importantly, when montelukast was added to imatinib, a significant increase in caspase activation was observed, compared to when imatinib was added alone. These results are in line with our previous observation, that addition of montelukast to imatinib induced additional inhibitory growth effects on CML cell lines and on primary CML patient cells (23). In addition to K562 we also assessed the CML cell line JURL-MK1 and again observed cleavage of the PARP-1 protein upon montelukast treatment. This indicates that apoptosis induction is not specific only for the K562 cell line but it is activated in other CML cell lines as well in response to montelukast treatment.

Various downstream signaling pathways are activated by CysLT1R in other malignancies $(11,27)$. Ligand binding to CysLT1R induces $\beta$-catenin nuclear translocation, translocation and activation of NF- $\kappa \mathrm{B}$, activation of transcription factor cAMP response element-binding protein (CREB), activation of the Ras/Raf/MEK/ERK pathway leading to proliferation, migration and survival. To better understand the mechanism of action of montelukast we aimed to ascertain whether montelukast alters these pathways in the CML cell line K562. Canonical Wnt pathway's downstream effector $\beta$-catenin is required for the progression of CML and maintenance of LSCs $(25,28,29)$. In active Wnt $/ \beta$-catenin signaling $\beta$-catenin is translocated into the nucleus where it activates the transcription of c-myc, survivin, and cyclin D1 resulting in proliferation of cells (29). Therefore genetic and pharmacologic inhibition of $\beta$-catenin can eradicate imatinib-resistant CML LSCs (25). If $\mathrm{Wnt} / \beta$-catenin signaling is negatively regulated, cytoplasmic $\beta$-catenin is phosphorylated and marked with ubiquitin mediated by $\beta$-transducin-repeat-containing protein $(\beta$-TrCP) for proteasome-dependent degradation (29). Montelukast induced phosphorylation of $\beta$-catenin, decreased expression of c-myc and enhanced interaction of $\beta$-catenin and $\beta$-TrCP. Although the full mechanisms remain to be elucidated, these observations suggest that montelukast is able to inhibit Wnt/ $\beta$-catenin signaling. We observed no alterations in NF- $\mathrm{NB}, \mathrm{CREB}$ or Ras/Raf/MEK/ERK pathway as a result of montelukast treatment (data not shown).

Taken together, our results indicate that addition of montelukast to imatinib may be a promising, novel clinical treatment option in CML, perhaps particularly beneficial for individual CML patients presenting with CysLT overexpression.

\section{Acknowledgements}

The authors would like to thank Dr Metka Novak for the valuable input regarding the cytochrome $c$ staining experiment.

\section{Funding}

The study was financially supported by Emil Andersson Fund for Medical Research, Medical Research Funds of Umeå University and Västernorrland County Council, the Cancer Research Foundations of Radiumhemmet, the National Board of Health and Welfare, Karolinska Institutet's foundations and funds.

\section{Availability of data and materials}

The datasets used during the present study are available from the corresponding author upon reasonable request.

\section{Authors' contributions}

$\mathrm{AZ}$ and EYK contributed equally to conception and design, acquisition, analysis and interpretation of data, writing and revising the manuscript. DS performed selected analyses and participated in data interpretation. LS contributed to the design, writing and critical revision of the manuscript. AN and JW were involved in the conception of the study. All authors read and approved the final manuscript.

\section{Ethics approval and consent to participate}

Not applicable.

\section{Consent for publication}

Not applicable.

\section{Competing interests}

The authors declare that they have no competing interests.

\section{References}

1. Heisterkamp N, Stam K, Groffen J, de Klein A and Grosveld G: Structural organization of the bcr gene and its role in the $\mathrm{Ph}^{\prime}$ translocation. Nature 315: 758-761, 1985.

2. Hoglund M, Sandin F, Hellström K, Björeman M, Björkholm M, Brune M, Dreimane A, Ekblom M, Lehmann S, Ljungman P, et al: Tyrosine kinase inhibitor usage, treatment outcome, and prognostic scores in CML: Report from the population-based Swedish CML registry. Blood 122: 1284-1292, 2013. 
3. Gambacorti-Passerini C, Antolini L, Mahon FX, Guilhot F, Deininger M, Fava C, Nagler A, Della Casa CM, Morra E, Abruzzese E, et al: Multicenter independent assessment of outcomes in chronic myeloid leukemia patients treated with imatinib. J Natl Cancer Inst 103: 553-561, 2011.

4. Morotti A, Panuzzo C, Fava C and Saglio G: Kinase-inhibitorinsensitive cancer stem cells in chronic myeloid leukemia. Expert Opin Biol Ther 14: 287-299, 2014.

5. Funk CD: Prostaglandins and leukotrienes: Advances in eicosanoid biology. Science 294: 1871-1875, 2001.

6. Chen Y, Hu Y, Zhang H, Peng C and Li S: Loss of the Alox 5 gene impairs leukemia stem cells and prevents chronic myeloid leukemia. Nat Genet 41: 783-792, 2009.

7. Chen Y, Li D and Li S: The Alox5 gene is a novel therapeutic target in cancer stem cells of chronic myeloid leukemia. Cell Cycle 8: 3488-3492, 2009.

8. Peters-Golden M, Gleason MM and Togias A: Cysteinyl leukotrienes: Multi-functional mediators in allergic rhinitis. Clin Exp Allergy 36: 689-703, 2006.

9. Ohd JF, Nielsen CK, Campbell J, Landberg G, Löfberg H and Sjölander A: Expression of the leukotriene D4 receptor CysLT1, COX-2, and other cell survival factors in colorectal adenocarcinomas. Gastroenterology 124: 57-70, 2003.

10. Matsuyama M and Yoshimura R: Cysteinyl-leukotriene1 receptor is a potent target for the prevention and treatment of human urological cancer. Mol Med Rep 3: 245-251, 2010.

11. Burke L, Butler CT, Murphy A, Moran B, Gallagher WM, O'Sullivan J and Kennedy BN: Evaluation of cysteinyl leukotriene signaling as a therapeutic target for colorectal cancer. Front Cell Dev Biol 4: 103, 2016.

12. Magnusson C, Liu J, Ehrnström R, Manjer J, Jirström K, Andersson T and Sjölander A: Cysteinyl leukotriene receptor expression pattern affects migration of breast cancer cells and survival of breast cancer patients. Int J Cancer 129: 9-22, 2011.

13. Zhang WP, Hu H, Zhang L, Ding W, Yao HT, Chen KD Sheng WW, Chen Z and Wei EQ: Expression of cysteinyl leukotriene receptor 1 in human traumatic brain injury and brain tumors. Neurosci Lett 363: 247-251, 2004.

14. Virchow JC and Bachert C: Efficacy and safety of montelukast in adults with asthma and allergic rhinitis. Respir Med 100: 1952-1959, 2006.

15. Matsuyama M, Funao K, Hayama T, Tanaka T, Kawahito Y, Sano H, Takemoto Y, Nakatani T and Yoshimura R: Relationship between cysteinyl-leukotriene-1 receptor and human transitional cell carcinoma in bladder. Urology 73: 916-921, 2009.

16. Matsuyama M, Hayama T, Funao K, Kawahito Y, Sano H, Takemoto Y, Nakatani T and Yoshimura R: Overexpression of cysteinyl LT1 receptor in prostate cancer and CysLT1R antagonist inhibits prostate cancer cell growth through apoptosis. Oncol Rep 18: 99-104, 2007.

17. Funao K, Matsuyama M, Naganuma T, Kawahito Y, Sano H, Nakatani T and Yoshimura R: The cysteinylLT1 receptor in human renal cell carcinoma. Mol Med Rep 1: 185-189, 2008.
18. Savari S, Liu M, Zhang Y, Sime W and Sjölander A: CysLT(1)R antagonists inhibit tumor growth in a xenograft model of colon cancer. PLoS One 8: e73466, 2013.

19. Sveinbjörnsson B, Rasmuson A, Baryawno N, Wan M, Pettersen I, Ponthan F, Orrego A, Haeggström JZ, Johnsen JI and Kogner P: Expression of enzymes and receptors of the leukotriene pathway in human neuroblastoma promotes tumor survival and provides a target for therapy. FASEB J 22: 3525-3536, 2008.

20. Piromkraipak P, Sangpairoj K, Tirakotai W, Chaithirayanon K, Unchern S, Supavilai P, Power C and Vivithanaporn P: Cysteinyl leukotriene receptor antagonists inhibit migration, invasion, and expression of MMP-2/9 in human glioblastoma. Cell Mol Neurobiol 38: 559-573, 2018.

21. Stenke L, Mansour M, Reizenstein P and Lindgren JA: Stimulation of human myelopoiesis by leukotrienes B4 and C4: interactions with granulocyte-macrophage colony-stimulating factor. Blood 81: 352-356, 1993

22. Stenke L, Samuelsson J, Palmblad J, Dabrowski L, Reizenstein P and Lindgren JA: Elevated white blood cell synthesis of leukotriene $\mathrm{C} 4$ in chronic myelogenous leukaemia but not in polycythaemia vera. Br J Haematol 74: 257-263, 1990.

23. Yektaei-Karin E, Zovko A, Nilsson A, Näsman-Glaser B, Kanter L, Rådmark O, Wallvik J, Ekblom M, Dolinska M, Qian $\mathrm{H}$, et al: Modulation of leukotriene signaling inhibiting cell growth in chronic myeloid leukemia. Leuk Lymphoma 58: 1903-1913, 2017.

24. Zhao C, Blum J, Chen A, Kwon HY, Jung SH, Cook JM, Lagoo A and Reya T: Loss of beta-catenin impairs the renewal of normal and CML stem cells in vivo. Cancer Cell 12: 528-541, 2007.

25. Heidel FH, Bullinger L, Feng Z, Wang Z, Neff TA, Stein L, Kalaitzidis D, Lane SW and Armstrong SA: Genetic and pharmacologic inhibition of $\beta$-catenin targets imatinib-resistant leukemia stem cells in CML. Cell Stem Cell 10: 412-424, 2012.

26. Reed JC: Proapoptotic multidomain Bcl-2/Bax-family proteins: Mechanisms, physiological roles, and therapeutic opportunities. Cell Death Differ 13: 1378-1386, 2006.

27. Savari S, Vinnakota K, Zhang Y and Sjölander A: Cysteinyl leukotrienes and their receptors: Bridging inflammation and colorectal cancer. World J Gastroenterol 20: 968-977, 2014.

28. Zhou H, Mak PY, Mu H, Mak DH, Zeng Z, Cortes J, Liu Q, Andreeff $\mathrm{M}$ and Carter BZ: Combined inhibition of $\beta$-catenin and Bcr-Abl synergistically targets tyrosine kinase inhibitor-resistant blast crisis chronic myeloid leukemia blasts and progenitors in vitro and in vivo. Leukemia 31: 2065-2074, 2017.

29. Zhang $X$ and Hao J: Development of anticancer agents targeting the Wnt/ $\beta$-catenin signaling. Am J Cancer Res 5: 2344-2360, 2015. 